\title{
Role of Modified Alvarado Score in the Diagnosis of Acute Appendicitis
}

\author{
${ }^{1}$ Dr Pradeep Goyal ${ }^{*},{ }^{2}$ Dr Arvind Kanwar, ${ }^{3}$ Dr Parikshit Malhotra, \\ ${ }^{4}$ Dr Dhruv Sharma, ${ }^{5}$ Dr Shiv Kumar Sharma \\ ${ }^{1}$ Assistant Professor Department Of Surgery Mmmch Kumarhatti Solan \\ ${ }^{2}$ Medical Officer District Hospital Dharmshala H.P. \\ ${ }^{3}$ Assistant Pro Fessor Department Of Surgery Indira Gandhi Medical College \& Hospital Shimla H.P. \\ ${ }^{4}$ Assistant Professor Department Of Surgery Indira Gandhi Medical College \& Hospital Shimla H.P. \\ ${ }^{5}$ Senior Resident Govt. Medical College \& Hospital Jaтmи $J \& K$
}

\section{Introduction}

Acute appendicitis has remained the most common diagnosis of emergency hospital admissions requiring laparotomy.[1,2] Approximately $6 \%$ of the population suffers from acute appendicitis during their lifetime. The mortality rate is less than $0.1 \%$ for non-complicated appendicitis, $0.6 \%$ in gangrenous appendicitis, and $5 \%$ for perforated cases. Therefore much effort has been directed towards early diagnosis and intervention.[3] The diagnosis of appendicitis can be difficult, occasionally taxing the diagnostic skills of even the most experienced surgeons. The classical signs and symptoms of acute appendicitis were first reported by Fitz in 1886.[4] As the incidence of perforation is usually proportional to the duration of the disease process, traditional teaching has encouraged surgeons to operate even if the diagnosis is probable rather than wait until it is certain. The morbidity and mortality rates associated with appendicectomy are greatly increased when perforation ensues.[5] There is three time increase in wound infection rate, fifteen fold increases in intra abdominal abscess and mortality may be 50 times greater.[3] Appendiceal perforation can also cause tubal infertility.[6] Hence aim of the surgeon must be to operate before perforation occurs, in spite of high rate of negative appendicectomy. The removal of normal appendix carries a price, the usual spectrum of immediate post-operative complications like hemorrhage, wound infection, intra-abdominal abscess in up to $15 \%$ of patients.[3] and late complications such as intestinal obstruction, incisional hernia[7], right sided inguinal hernia[8] and sterility due to fimbrial adhesions.[9] Hence 20-44\% negative apendicectomy rate which surgeons hence hitherto accepted, can no longer be justified.[10] Despite extraordinary advances in modern imaging and other diagnostic investigations, the accurate pre-operative diagnosis of acute appendicitis remains an enigmatic challenge. Scoring systems appear to be ideal, convenient accurate, non-invasive and require no special equipment. Modified Alvarado's score is the most simple to use, easy to apply and is also dynamic since it relies only on history, clinical examination and basic laboratory investigations.[11] The present study aims to evaluate the usefulness of the modified Alvarado Scoring system in the preoperative diagnosis of acute appendicitis to reduce the false positive appendicectomy rate.

\section{Material And Methods}

Present study was carried out in I.G. Medical College and Hospital, on admitted patients, of right iliac fossa (RIF) pain and suspected cases of acute appendicitis during the period of one year from 01-01-2013 to 3112-2013 and included 50 patients. The evaluation of the patients was done by history, clinical examination, Modified Alvarado Score, investigations and histopathological examination of appendicectomy specimen. Detailed history was taken in every case with emphasis on migratory RIF pain, anorexia, nausea / vomiting, burning micturation, fever, menstrual history and history of tuberculosis. Every case was thoroughly examined and with emphasis on recording of pulse, temperature, tenderness in right iliac fossa, rebound tenderness in right iliac fossa, digital rectal examination was done. The tests done on admitted patients with right iliac fossa pain, were $\mathrm{Hb}$, TLC, DLC, ESR, random blood sugar, serum urea, serum creatinine. Urine for albumin, sugar and microscopic examination. Histopathological examination of appendix in all operated cases was done. The patients with right iliac fossa pain were subjected to Chest radiograph - PA view, radiograph Abdomen (standing) and USG - Abdomen (using high frequency transducer).

\section{Modified Alvarado Score}

The scoring system as described is based on 3 symptoms, 3 signs and 1 laboratory test.[12]

\begin{tabular}{|l|l|}
\hline MODIFIED ALVARADO SCORING SYSTEM & \\
\hline FEATURES & SCORE \\
\hline Symptoms & \\
\hline
\end{tabular}


Role of Modified Alvarado Score in the Diagnosis of Acute Appendicitis

\begin{tabular}{|l|l|}
\hline$>$ & 1 \\
\hline$>$ & Migratory RIF pain \\
\hline$>$ & 1 \\
\hline Signs Nausea / vomiting & 1 \\
\hline$>\quad$ Tenderness RIF & \\
\hline$>\quad$ Rebound tenderness RIF & 2 \\
\hline$>\quad$ Elevated temperature $\left(\geq 37.5^{\circ} \mathrm{C}\right)$ & 1 \\
\hline Laboratory & 1 \\
\hline$>\quad$ Teucocytosis $\left(>10 \times 10^{9} / \mathrm{L}\right)$ & \\
\hline$>\quad$ & 2 \\
\hline
\end{tabular}

In this study, we used modified version of the Alvarado score by excluding one laboratory findings ; shift to the left of neutrophil maturation (> 75\%). Patients with Modified Alvarado Score of 1-4 are considered unlikely to have acute appendicitis, those with a score of 5-6 have a possible diagnosis of acute appendicitis, not convincing enough to have urgent surgery, and those with score of 7-9 are regarded as probable acute appendicitis. The Modified Alvarado Score can increase or decrease on reassessment. The diagnosis made by Modified Alvarado Score and confirmed with operative findings i.e. appendix inflamed or not, gangrene of appendix present or not, periappendicular fluid is present or not and histopathological examination of appendix in all operated cases. Sensitivity and specificity of our new method was compared to standard coated data in literature.

\section{Observations}

The youngest case was 6 years old and the oldest was 55 years of age. The mean age was $25.50 \pm 12.63$ years. It was observed that maximum number of $13(26 \%)$ cases belong to $21-30$ years of age group and minimum number of $1(2 \%)$ cases belongs to $41-50$ years of age group. In our study, 33 (66\%) cases were males and $17(34 \%)$ cases were females.

On assessment, the patients were categorized into 3 groups as mentioned in Table 1

In our study, out of 50 patients 24 patients were male and 14 patients were female and 12 were children (Table 1)

Table : 1 - Showing group - wise distribution of cases

\begin{tabular}{|l|l|l|}
\hline Groups & No. of patients(n-50) & Percentage(\%) \\
\hline Male (group I) & 24 & 48 \\
\hline Female (group II) & 14 & 28 \\
\hline Children(group III) & 12 & 24 \\
\hline Total & $\mathbf{5 0}$ & $\mathbf{1 0 0}$ \\
\hline
\end{tabular}

In our study, we observed that migratory pain was present in 36(72\%) cases with history of pain around the umbilical region initially which later shifted to RIF. Anorexia was present in 44(88\%) of cases. Nausea / vomiting was present in $42(84 \%)$ of cases . Elevated temperature was present in $28(56 \%)$ of cases. Rebound tenderness was present in $43(86 \%)$ of cases. Tenderness RIF was present in 50(100\%) of cases. Leucocytosis was seen in $35(70 \%)$ of cases. (Table 2)

Table : 2 - Showing symptoms, Signs and Lab findings

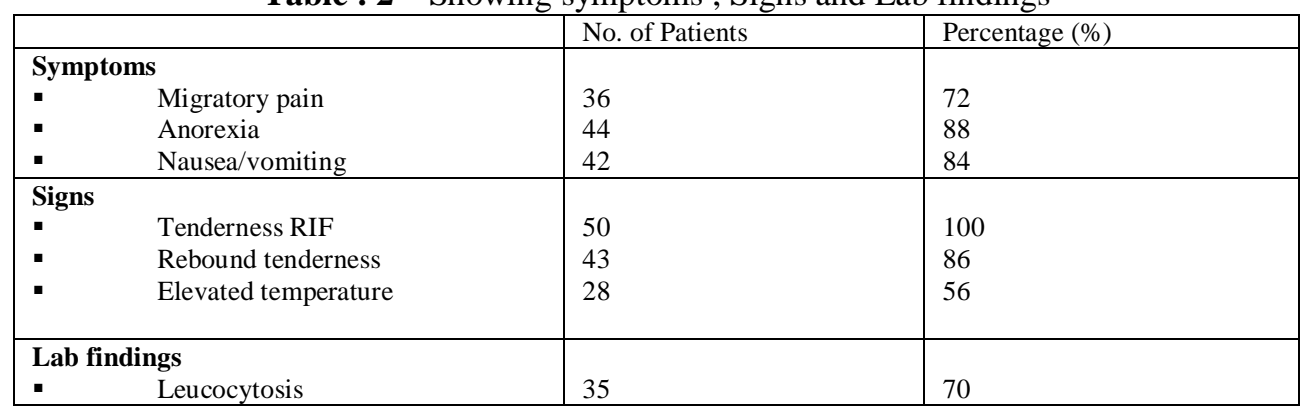

\section{Group - wise distribution of chief symptoms}

In our study we observed that $20(83.3 \%)$ cases presented with migratory pain RIF, $18(75 \%)$ were having anorexia and $16(66.67 \%)$ were having nausea / vomiting in group I (n - 24). In group II (n - 14), 5 (35.7\%) cases were presented with migratory pain RIF, anorexia and nausea / vomiting were present in $14(100 \%)$ patients each. Whereas in group III $(\mathrm{n}-12), 11$ cases presented with migratory pain RIF and all the $12(100 \%)$ cases were having anorexia and nausea / vomiting.(Table 3 ) 
Table : 3 - showing group - wise distribution of chief symptoms

\begin{tabular}{|l|l|l|l|}
\hline Symptoms & No. of cases in group I (n-24) & No. of cases in group II (n-14) & No. of cases in group III (n-12) \\
\hline Migratory pain RIF & $20(83.3 \%)$ & $05(35.7 \%)$ & $11(91.66 \%)$ \\
\hline Anorexia & $18(75 \%)$ & $14(100 \%)$ & $12(100 \%)$ \\
\hline Nausea / vomiting & $16(66.67 \%)$ & $14(100 \%)$ & $12(100 \%)$ \\
\hline
\end{tabular}

\section{Group - wise distribution of chief signs}

It was observed that all $24(100 \%)$ cases were having tenderness RIF , rebound tenderness was present in $21(87.5 \%)$ cases and elevated temperature was present in $11(45.8 \%)$ cases in group I . In group II, 14 (100\%) cases were having tenderness RIF, 11(78.5\%) cases were having rebound tenderness and 9(64.2\%) cases were having elevated temperature. In group III, 12(100\%) cases were having tenderness RIF , 11(91.6\%) cases were having rebound tenderness and $8(66.6 \%)$ cases were having elevated temperature .(Table 4$)$

Table : 4 - showing group - wise distribution of chief signs

\begin{tabular}{|l|l|l|l|}
\hline Symptoms & No. of cases in group I (n-24) & No. of cases in group II (n-14) & No. of cases in group III (n-12) \\
\hline Tenderness RIF & $24(100 \%)$ & $14(100 \%)$ & $12(100 \%)$ \\
\hline Rebound tenderness & $21(87.5 \%)$ & $11(78.5 \%)$ & $11(91.6 \%)$ \\
\hline Elevated temperature & $11(45.8 \%)$ & $09(64.2 \%)$ & $08(66.6 \%)$ \\
\hline
\end{tabular}

\section{Group - wise distribution of laboratory findings}

In our study, we observed that $15(62.5 \%)$ cases were having leucocytosis in group I (n-24). In group II $(\mathrm{n}-14), 11(78.6 \%)$ cases were having Leucocytosis, whereas in group III (n-12), 9(75\%) cases were having Leucocytosis.

\section{Group-wise distribution of cases with Modified Alvarado Score $\geq 7$}

In our study, out of total 24 cases in group I, 17 (70.8\%) cases were having Modified Alvarado Score $\geq$ 7. In group II (n-14), $12(85.7 \%)$ cases were having Modified Alvarado Score $\geq 7$ whereas in group III (n12), $11(91.6 \%)$ cases were having Modified Alvarado Score $\geq 7$.

All cases with Modified Alvarado Score $\geq 7$ underwent an appendicectomy (Table 5)

Table : $\mathbf{5}$ - showing group - wise distribution of cases with Modified Alvarado Score $\geq 7$

\begin{tabular}{|l|l|l|}
\hline Group & No. of patients(n-50) & No. of patients with MAS $\geq 7$ \\
\hline Group I & 24 & $17(70.8 \%)$ \\
\hline Group II & 14 & $12(85.7 \%)$ \\
\hline Group III & 12 & $11(91.6 \%)$ \\
\hline
\end{tabular}

\section{Group wise distribution of cases with Modified Alvarado Score $<7$}

In group I, out of 24 patients , 5 were having Modified Alvarado Score 6 and 2 were having Modified Alvarado Score 5 , who were thought on clinical ground to require appendicectomy after 24 hour observation , because still they were having persistent pain in RIF associated with vomiting and tenderness in RIF along with other associated criteria.

In group II , out of 14 cases , 1 case was having Modified Alvarado Score 6 and 1 was having Modified Alvarado Score 5 , who were thought on clinical ground to require appendicectomy after 24 hour observation , because till they were having persistent pain in RIF associated with vomiting and tenderness in RIF along with other associated criteria

In group III , 1 case was having Modified Alvarado Score 6 who were thought on clinical ground to require appendicectomy after 24 hour observation, because still he was having persistent pain in RIF associated with vomiting and tenderness in RIF along with other associated criteria.

All the patients who had modified Alvarado Score $<5$ were discharged after inpatients observation. In these patients the condition did not progress further and none of the patients developed an appendix mass or generalized peritonitis from perforation. All the patients who had low score $<5$ were discharged and did not subsequently report for an appendicectomy (Table 6)

Table:6 - showing group - wise distribution of cases with Modified Alvarado Score < 7

\begin{tabular}{|l|l|l|l|}
\hline Groups & Total no. of patients (n-50) & No. of patients with MAS 6 & No. of patients with MAS 5 \\
\hline Group I & 24 & 5 & 2 \\
\hline Group II & 14 & 1 & 1 \\
\hline Group III & 12 & 1 & - \\
\hline
\end{tabular}

Appendicectomy in patients having Modified Alvarado Score $\geq 7$ showing false positive appendicectomy rates and sensitivity of Modified Alvarado Score 
In group I , appendicitis was confirmed histological in 15 of the 17 cases who underwent appendicectomy, a sensitivity of $93.75 \%$ (proportion of true positive). Two cases were included as false positive appendicectomy. In group II appendicitis was confirmed histological in 8 of the 12 cases who underwent appendicectomy, a sensitivity of $66.66 \%$ (proportion of true positive). 4 cases were included as false positive appendicectomy. In addition in group III, 11 children out of 12 has histological proven appendicitis producing a sensitivity rate $91.66 \%$ (Table 7 )

Table:7 showing sensitivity of Modified Alvarado Score in patients with MAS $\geq 7$

\begin{tabular}{|l|l|l|l|l|l|}
\hline Groups & $\begin{array}{l}\text { Total no. of patients } \\
(\mathrm{n}-50)\end{array}$ & $\begin{array}{l}\text { No. of patients with } \\
\text { MAS > 7 }\end{array}$ & Appendicitis & $\begin{array}{l}\text { False } \\
\text { appendicectomy }\end{array}$ & Sensitivity \\
\hline I & 24 & 17 & 15 & 2 & $93.75 \%$ \\
\hline II & 14 & 12 & 8 & 4 & $66.66 \%$ \\
\hline III & 12 & 11 & 11 & - & $91.66 \%$ \\
\hline
\end{tabular}

Appendicectomy in patients having modified Alvarado score $<7$ showing false positive appendicectomy rates and sensitivity of Modified Alvarado Score

It was observed that patients who went to operation theatre with Modified Alvarado Score of $<7$, seven were male, two were female and one child. Of these 6 of male had histological proven appendicitis producing a sensitivity rate of $69 \%$ and one of the two women had histological proven appendicitis producing a sensitivity rate of $50 \%$ (Table 8 )

Table:8 showing sensitivity of Modified Alvarado Score in patients with MAS < 7

\begin{tabular}{|l|l|l|l|l|l|}
\hline Groups & $\begin{array}{l}\text { Total no. of } \\
\text { patients (n-50) }\end{array}$ & $\begin{array}{l}\text { No. of patients } \\
\text { with MAS }<7\end{array}$ & Appendicitis & False positive appendicectomy & Sensitivity \\
\hline I & 24 & 7 & 6 & 1 & $69.00 \%$ \\
\hline II & 14 & 2 & 1 & 1 & $50.00 \%$ \\
\hline III & 12 & 1 & 1 & - & - \\
\hline
\end{tabular}

These patients were the only ones to have their diagnosis delayed, but this was not directly attributable to the scoring systems and they would have been observed for a period regardless. No patients required surgery who had a score of less than 5. In our study we found that the mean postoperative hospital stay was $4.06 \pm 0.68$ days.

\section{Discussion}

Appendicitis is a common surgical emergency. The diagnosis is generally based on history and physical examination, supported by hematological and radiological tests. Modified Alvarado Score is simple to use, easy to apply, and is dynamic since it relies on history, clinical examination and basic laboratory investigations. The present study was designed to evaluate the Modified Alvarado score in the diagnosis of acute appendicitis. In our study, mean age was 25.5(SD+12.63), male were 33(66\%) and females were $17(34 \%)$ comparable to the study conducted by Berry J and Malt RA (1984) ${ }^{13}$, where males were $148(60.2 \%)$ and females were $98(39.8 \%)$ and to the study conducted by Asfar S et al (2000) ${ }^{14}$, where males were $54(69.5 \%)$ and females were $24(30.5 \%)$. In our series maximum cases were from age group 21-30 (26\%) years while in study conducted by Lewis FR et al (1974) $)^{10}$, maximum cases were from age group 21-30 (35.5\%) years. The chief symptoms and the signs in our study were compared with the studies conducted by Lewis FR et al ${ }^{10}$ and Berry J, Malt RA (1984) ${ }^{13}$ and found to be in consistent with their findings as shown in the Table 1.

Table 1: Comparison of present study with other studies

\begin{tabular}{|l|l|l|l|}
\hline Variables & $\begin{array}{l}\text { Lewis FR et al } \\
(1974)^{10} \\
(\mathrm{n}-772)\end{array}$ & $\begin{array}{l}\text { Berry J and Malt RA (1984) } \\
(\mathrm{n}-246)\end{array}$ & $\begin{array}{l}\text { Present } \\
(2013) \\
(\mathrm{n}-50)\end{array}$ \\
\hline Anorexia & $92 \%$ & $61 \%$ & $88 \%$ \\
\hline Nausea/vomiting & $78 \%$ & $67.5 \%$ & $84 \%$ \\
\hline Migrated pain & $75 \%$ & $80 \%$ & $72 \%$ \\
\hline Elevated temperature & $13 \%$ & $34.3 \%$ & $56 \%$ \\
\hline Tenderness & $99 \%$ & $95.9 \%$ & $100 \%$ \\
\hline Rebound tenderness & $68 \%$ & $69.5 \%$ & $86 \%$ \\
\hline
\end{tabular}

In our study, leukocytosis was present in $35(70 \%)$ cases. Study conducted by Sasso RD et al (1970) ${ }^{15}$ showed that $80-82 \%$ of patients with acute appendicitis had a total white cell count of $10,000 / \mathrm{mm}^{3}$ Neutrophila of more than $75 \%$ occurred in $78 \%$ of patients. Doraiswamy NV (1979) ${ }^{16}$ had reported that the white cell count and neutrophil count are especially sensitive in children. Thus although a raised white cell count is highly sensitive test for acute appendicitis, is rendered almost useless by its low specificity and it has little diagnostic value. The only value of the 
white cell count would seem to be to prompt observation rather than operation in a patient who has equivocal feature of appendicitis together with normal count.

In our study, sensitivity of Modified Alvarado Score in male, female and children was $93.75 \%, 66.66 \%$ and $91.66 \%$ respectively in cases with MAS _> 7 with false positivity rate $5.25 \%, 33.34 \%, 8.34 \%$ respectively. Owen TD el al (1992) ${ }^{17}$ showed $94 \%, 78 \%$ and $88 \%$ sensitivity in men, women and children respectively in cases with Modified Alvarado Score > 7. Whereas false positivity rate of 6\%,22\% and $12 \%$ in men women and children respectively. Kalan $\mathrm{M}$ et al (1994) ${ }^{12}$ showed $93 \%, 67 \%$ and $100 \%$ sensitivity in men, women and children respectively in cases with Modified Alvarado Score _> 7. The negative appendicectomy rate in women was $33 \%$.

\section{Conclusion}

Acute appendicitis is of the commonest yet difficult diagnostic problems confronting the surgeon. The patient may not have typical clinical findings. Therefore making the exact diagnosis is problematic. The study showed that use of Modified Alvarado Score in patients suspected of having acute appendicitis provides a high degree of sensitivity and specificity. The Modified Alvarado Scoring system is effective in men and children but additional use of ultrasonography or diagnostic laparoscopy can be advised to minimize the unacceptably high false positive rate in women. Hence it is recommended that Modified Alvarado Score should be applied in cases of acute appendicitis.

\section{References}

[1]. Gilmore OJ, Browett JP, Griffin PH, Ross IK, Brodribb AJ, Cooke TJ, et al Appendicitis and mimicking conditions. A prospective study. Lancet. 1975 Sep 6; 2 (7932): 421-424

[2]. Chang FC, Hogle HH, Welling DR. The fate of the negative appendix. Am J Surg. 1973; 126(6):752-754.

[3]. Editorial. A sound approach to the diagnosis of acute appendicitis. Lancet 1987; 1: 198-200.

[4]. Fitz RH. Perforation inflammation of the vermiform appendix: with special reference to its early diagnosis and treatment. Am $\mathbf{J}$ Med Sic 1886; 92:321-346.

[5]. Jess P, Bjerregaard B, Brynitz S, Holst-Christensen J, Kalaja E, Lund-Kristensen J. Acute appendicitis Prospective trial concerning diagnostic accuracy and complications. Am J Surg. 1981; 141 (2): 232-234.

[6]. Mueller BA, Daling JR, Moore DE, Weiss NS, Spadoni LR, Stadel BV et al. Appendectomy and the risk of tubal infertility. N Engl J Med. 1986 11; 315(24): 1506-1508.

[7]. Van Way CW III, Murphy JR, Dunn EI, Elerding SC. A feasibility study of computer aided diagnosis in appendicitis. Surg Gynecol Obstet 1982; 155:685-688.

[8]. Arnbjornsson E. Development of right inguinal hernia after appendectomy. Am J Surg 1982; 143:174-175.

[9]. Spirtos NM, Eisenkop SM, Spirtos TW, Poliakin RI, Hibbard LT. Laparoscopy-a diagnostic aid in cases of suspected appendicitis. Its use in women of reproductive age. Am J Obstet Gynecol 1987; 156:90-94.

[10]. Lewis FR, Holcroft JW, Boey J, Dunphy E. Appendicitis. A critical review of diagnosis and treatment in 1,000 cases. Arch Surg. 1975; 110(5): 677-684.

[11]. Hoffman J Rasmussen OO. Aids in the diagnosis of acute appendicitis. Br J Surg 1989; 76:774-79.

[12]. Kalan M, Talbot D, Cuniiffi WJ, Rich AJ. Evaluation of the Modified Alvarado Score in the diagnosis of acute appendicitis: A prospective study. Ann R Coll Surg Engl 1994; 76(6):418-419.

[13]. Berry J Jr, Malt RA. Appendicitis near its centenary. Ann Surg. 1984; 200(5): 567-575.

[14]. Asfar S, Safar H, Khoursheed M, Dashti H, al-Bader A. Would measurement of C-reative protein reduce the rate of negative exploration for acute appendicitis ? J R Coll Surg Edinb.2000; 45(1):21-24.

[15]. Sasso RD, Hanna EA, Moore DL. Leukocytic and neutrophilic counts in acute appendicitis. Am J Surg. $1970 ; 120(5): 563-566$.

[16]. Doraiswamy NV. Leucocyte counts in the diagnosis and prognosis of acute appendicitis in children. Br J Surg. 1979; 66(11):782784.

[17]. Owen TD, Williams H, Stiff G, Jenkinson LR, Rees BI. Evaluation of the Alvarado score in acute appendicitis. Journal of the Royal Society of Medicine 1992; 85 (2): 87-88. 